Article

\title{
5,6-Didehydroginsenosides from the Roots of Panax notoginseng
}

\section{Jian-Bo Wan ${ }^{1,2}$, Qing-Wen Zhang ${ }^{1}$, , Si-Jia Hong ${ }^{1}$, Jia Guan ${ }^{1}$, Wen-Cai Ye ${ }^{3}$, Shao-Ping Li ${ }^{1}$, Ming-Yuen Simon Lee ${ }^{1}$ and Yi-Tao Wang ${ }^{1, *}$}

1 Institute of Chinese Medical Sciences, University of Macau, Taipa, Macao, China;

E-Mails: wjbcpu@hotmail.com (J.-B.W.); brendajia0901@hotmail.com (S.-J.H.); ya67402@umac.mo (J.G.); spli@umac.mo (S.-P.L.); simonlee@umac.mo (M.-Y.S.L.)

2 Department of Medicine, Massachusetts General Hospital and Harvard Medical School, Boston, MA 02114, USA

3 Institute of Traditional Chinese Medicine and Natural Products, College of Pharmacy, Jinan University, Guangzhou, 510632, China; E-Mail: chywc@yahoo.com.cn (W.-C.Y.)

* Authors to whom correspondence should be addressed; E-Mails: qwzhang@umac.mo (Q.-W.Z.), ytwang@umac.mo (Y.-T.W.); Tel.: +853 83974879 (Q.-W.Z.), +853 83974691 (Y.-T.W.); Fax: +853-2884 1358 .

Received: 3 November 2010; in revised form: 8 November 2010 / Accepted: 10 November 2010 / Published: 11 November 2010

\begin{abstract}
Two minor novel dammarane-type saponins - 5,6-didehydroginsenoside $\mathrm{Rd}(\mathbf{1})$ and 5,6-didehydroginsenoside Rb1 (2)-were isolated from the dried roots of Panax notoginseng along with sixteen known saponins. The structures of the new compounds were elucidated on the basis of spectroscopic and chemical methods.
\end{abstract}

Keywords: Panax notoginseng; triterpene saponins; didehydroginsenosides

\section{Introduction}

Root of Panax notoginseng (Burk.) F. H. Chen (Araliaceae), also called Sanqi, is a well-known herb commonly used as a medicine and dietary supplement. It has been cultivated commercially in the southwest regions of China, especially in the Wenshan region, Yunnan Province. P. notoginseng has been used in China as a drug for the treatment of haemoptysis, haemostatic and haematoma for more than 400 years [1]. Current pharmacological studies revealed that $P$. notoginseng and its ingredients 
possess anticarcinogenic [2,3], immunoregulatory [4], anti-inflammatory [5], anti-arrhythmic [6], hepatoprotective [7] properties, as well as protective effects on cardiovascular and cerebrovascular systems [1,8-9]. Drammarane type saponins are considered as the major bioactive constitutes in $P$. notoginseng [1,10-12].

During our studies on the screening of bioactive ingredients from medicinal herbs with activity against vascular inflammation, the glycosidic fraction from the roots of $P$. notoginseng was observed to reduce atherosclerotic lesions in apoE deficient mice, an effect which may be responsible for its inhibitory action on vascular inflammation [13]. During further study on this fraction, two novel triterpene saponins, 5,6-didehydroginsenoside $\mathrm{Rd}(\mathbf{1})$ and 5,6-didehydroginsenoside Rb1 (2) (Figure $1)$, were isolated from the methanolic extract of the roots together with sixteen known dammaranetype saponins. We report herein the structure elucidation of these components.

Figure 1. Structures of compounds 1 and 2.

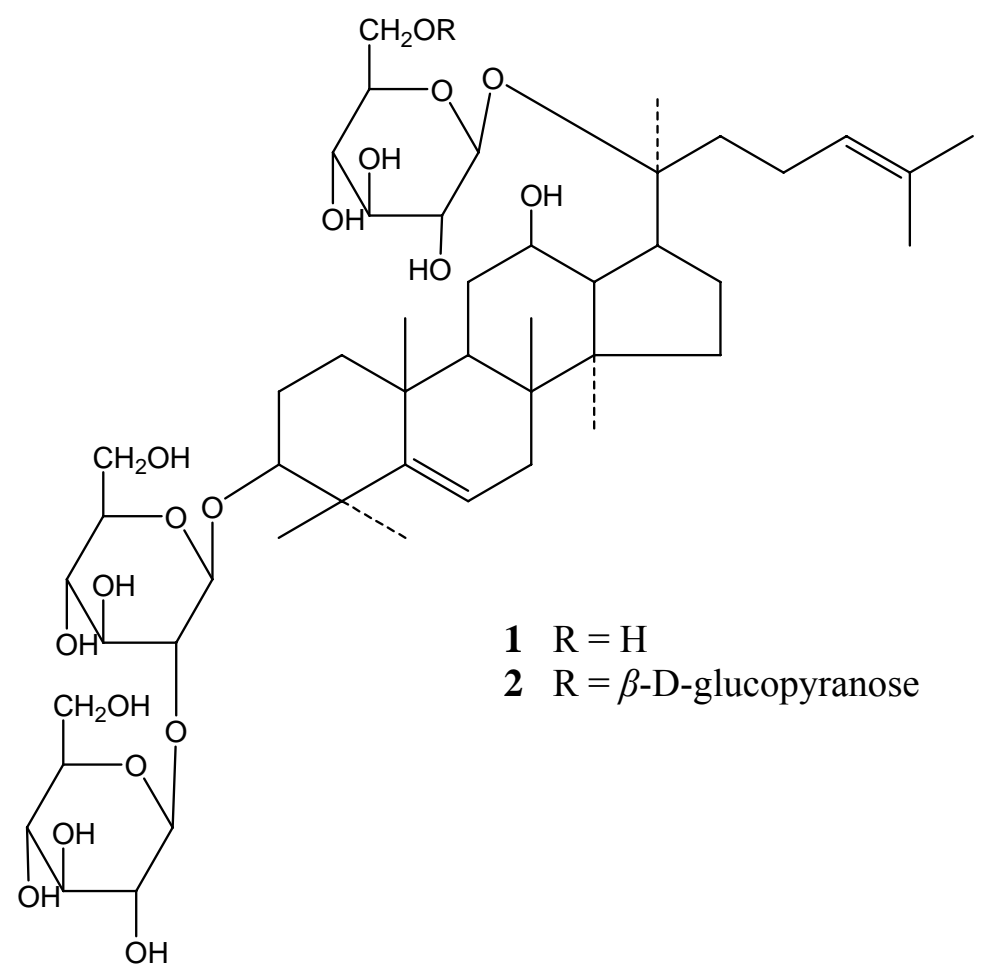

\section{Results and Discussion}

The methanol extract of the dried roots of $P$. notoginseng was subjected to D-101 macroporous adsorption resin separation and chromatographed repeatedly on ordinary and reverse phase silica-gel columns, and finally on preparative high-performance liquid chromatography (prep-HPLC) to afford eighteen saponins 1-18. The spectroscopic data of compounds 3-18 were identical with those of notoginsenosides R1 (3), R2 (6) [14], Fa (10) [15], R4 (11) [16], T (12) [17], K (17) [18], ginsenosides Rg1 (4) [19], Re (5), Rg2 (7) [14,20], Rh1 (8) [14], Ra3 (13) [21], Rb1 (14), Rd (16) [22], chikusetsusaponin L5 (9) [23], malonyl-ginsenoside Rb1 (15) [24] and quinquenoside R1 (18) [25], which were isolated previously from Panax genus plants. Compounds 9, 15 and $\mathbf{1 8}$ were thus isolated 
for the first time from the roots of $P$. notoginseng. The structures of the new saponins 1-2 were determined on the basis of spectroscopic and chemical methods described as follows.

Compound 1 was obtained as a white amorphous solid. The negative ion ESI-MS of 1 showed a quasimolecular ion [M-H] $]^{-}$at $m / z$ 943, consistent with a molecular formula of $\mathrm{C}_{48} \mathrm{H}_{80} \mathrm{O}_{18}$. Compound 1 exhibited a mass difference of 2 in comparison to ginsenoside Rd (16). Acid hydrolysis of 1 afforded glucose as the only sugar component. The ${ }^{1} \mathrm{H}-\mathrm{NMR}$ spectrum of $\mathbf{1}$ displayed signals due to eight tertiary methyls at $\delta_{\mathrm{H}} 0.91,0.99,1.09,1.42,1.49,1.58(2 \times \mathrm{CH} 3)$ and 1.61 , and two olefinic protons at $\delta_{\mathrm{H}} 5.59$ and 5.24 for the aglycon moiety. The ${ }^{1} \mathrm{H}$ - and ${ }^{13} \mathrm{C}-\mathrm{NMR}$ (Table 1) spectra of 1 showed signals assignable to three $\beta$-D-glucopyranosyl moieties $\left[\delta_{\mathrm{H}} 4.87\left(1 \mathrm{H}, \mathrm{d}, J=7.5 \mathrm{~Hz}, \mathrm{H}-1^{\prime}\right), 5.17(1 \mathrm{H}, \mathrm{d}\right.$, $\left.J=7.8 \mathrm{~Hz}, \mathrm{H}-1^{\prime \prime \prime}\right)$ and $\left.5.34(1 \mathrm{H}, \mathrm{d}, J=7.1 \mathrm{~Hz}, \mathrm{H}-1 ")\right]$. Further analysis of the NMR data suggested that the aglycon of 1 could be a substituted dammarane-type triterpene. The ${ }^{1} \mathrm{H}$ - and ${ }^{13} \mathrm{C}$-NMR resonances of the sapogenin moiety of $\mathbf{1}$ are very similar to that of the protopanaxadiol bisdemosidic saponins such as ginsenoside Rd and Rb1 [16,26-27], except for signals of ring B, C-4, C-11, C-19, C-28 and C29 and the presence of an additional olefin group ( $\delta_{\mathrm{H}} 5.59$ and $\delta_{\mathrm{C}} 119.8$ and 147.4), suggesting that 1 could be a dehydroprotopanaxadiol bisdemosidic saponin. The additional double bond was assigned to C-5 and C-6 from the correlations in HMBC spectra between C-5 $\left(\delta_{\mathrm{C}} 147.4\right)$ and $19-\mathrm{H}_{3}\left(\delta_{\mathrm{H}} 1.09\right)$, 28$\mathrm{H}_{3}\left(\delta_{\mathrm{H}} 1.49\right)$ and $29-\mathrm{H}_{3}\left(\delta_{\mathrm{H}} 1.42\right)$, and between $\mathrm{H}-6\left(\delta_{\mathrm{H}} 5.59\right)$ and $\mathrm{C}-5\left(\delta_{\mathrm{C}} 147.4\right), \mathrm{C}-4\left(\delta_{\mathrm{C}} 43.0\right)$ and C$10\left(\delta_{\mathrm{C}} 37.3\right)$. The ${ }^{13} \mathrm{C}-\mathrm{NMR}$ data also suggested 1 had the same sugar chains and glycosidic locations with that of ginsenoside $\mathrm{Rd}$ (27). Location of a $\beta$-sophorosyl moiety at $\mathrm{C}$-3 position of the aglycon was confirmed by HMBC correlations between carbon signals at $\delta_{\mathrm{C}} 88.0$ (C-3), 104.9(C-1'), 83.7(C-2') and proton signals at $\delta_{\mathrm{H}} 4.87\left(\mathrm{H}-1^{\prime}\right), 3.30(\mathrm{H}-3), 5.34(\mathrm{H}-1 ")$, respectively. Similarly, a long-range correlation between the carbon signal at $\delta_{\mathrm{C}} 83.3$ (C-20) and the proton signal at $\delta_{\mathrm{H}} 5.17\left(\mathrm{H}-1{ }^{\prime \prime \prime}\right)$ ascertained that a $\beta$-D-glucopyranosyl unit is located at the $\mathrm{C}-20$ of the sapogenin. Thus, the structure of compound 1 was determined as 3-O- $\beta$-D-glucopyranosyl-(2-1)- $\beta$-D-glucopyranosyl 5,6-didehydro20(S)-protopanaxadiol 20-O- $\beta$-D-glycopyranoside (5,6-didehydroginsenoside $\mathrm{Rd}$ ).

Compound 2 was obtained as white amorphous powder. The spectra of 2 were in part similar to those of 1. The negative ion ESI-MS of 2 displayed quasimolecular ion peak at $\mathrm{m} / \mathrm{z} 1,105[\mathrm{M}-\mathrm{H}]^{-}$, consistent with a molecular of $\mathrm{C}_{54} \mathrm{H}_{90} \mathrm{O}_{23}$, which suggested the presence of an extra hexose unit in 2 compared to $\mathbf{1}$. Acid hydrolysis of 2 afforded D-glucose. Further comparison of the ${ }^{13} \mathrm{C}$-NMR data of 2 (Table 1) with that of $\mathbf{1}$ and ginsenoside Rb1 revealed that the sapogenin and sugar chains of 2 were the same as that of 1 and ginsenoside Rb1 [16], respectively. The above finding was supported by the HMBC experiment. Long range correlation signals were observed between carbon resonances at C-5 $\left(\delta_{\mathrm{C}} 147.4\right)$ and $19-\mathrm{H}_{3}\left(\delta_{\mathrm{H}} 1.09\right), 28-\mathrm{H}_{3}\left(\delta_{\mathrm{H}} 1.49\right)$ and $29-\mathrm{H}_{3}\left(\delta_{\mathrm{H}} 1.42\right)$, between $\mathrm{H}-6\left(\delta_{\mathrm{H}} 5.59\right)$ and $\mathrm{C}-5$ $\left(\delta_{\mathrm{C}} 147.4\right), \mathrm{C}-4\left(\delta_{\mathrm{C}} 43.0\right)$ and $\mathrm{C}-10\left(\delta_{\mathrm{C}} 37.3\right)$, between $\mathrm{H}-1 "\left(\delta_{\mathrm{H}} 5.34\right)$ of terminal glucose and C-2' $\left(\delta_{\mathrm{C}}\right.$ 83.6) of inner glucose, and between H-1' $\left(\delta_{\mathrm{H}} 4.88\right)$ of inner glucose and C-3 $\left(\delta_{\mathrm{C}} 87.9\right)$ of the aglycon. Moreover, HMBC spectrum revealed correlation between H-1"'" $\left(\delta_{\mathrm{H}} 5.04\right)$ of additional terminal glucose and C-6"' $\left(\delta_{\mathrm{C}} 70.3\right)$ of the bridging glucose as well as the correlation between $\mathrm{H}-1$ "' $\left(\delta_{\mathrm{H}} 5.12\right)$ of the bridging glucose and C-20 $\left(\delta_{\mathrm{C}} 83.4\right)$ of the aglycon. All above evidence led the identification of 2 as 3- $O-\beta$-D-glucopyranosyl-(2-1)- $\beta$-D-glucopyranosyl-5,6-didehydro-20(S)-protopanaxadiol-20- $O-\beta$ D-glucopyranosyl-(6-1)- $\beta$-D-glucopyranoside (5,6-didehydroginsenoside Rb1). 
Table 1. ${ }^{13} \mathrm{C}$ NMR data of compounds 1 and 2 (in $\mathrm{C}_{5} \mathrm{D}_{5} \mathrm{~N}, \delta$ in ppm).

\begin{tabular}{|c|c|c|c|c|c|}
\hline $\mathrm{C}$ & 1 & 2 & $\mathrm{C}$ & 1 & 2 \\
\hline 1 & 39.7 & 39.7 & 3-O-Sugar & glc & glc \\
\hline 2 & 27.0 & 27.0 & $1^{\prime}$ & 104.9 & 104.9 \\
\hline 3 & 88.0 & 87.9 & $2^{\prime}$ & 83.7 & 83.6 \\
\hline 4 & 43.0 & 43.0 & $3^{\prime}$ & 78.0 & 78.0 \\
\hline 5 & 147.4 & 147.4 & $4^{\prime}$ & 71.7 & 71.7 \\
\hline 6 & 119.8 & 119.7 & $5^{\prime}$ & 78.3 & 78.3 \\
\hline 7 & 34.8 & 34.8 & $6^{\prime}$ & 63.0 & 62.9 \\
\hline 8 & 37.2 & 37.2 & & $\operatorname{glc}(1-2)$ & $\operatorname{glc}(1-2)$ \\
\hline 9 & 47.2 & 47.1 & $1 "$ & 106.2 & 106.1 \\
\hline 10 & 37.3 & 37.3 & $2 "$ & 77.1 & 77.0 \\
\hline 11 & 32.6 & 32.4 & 3" & 78.0 & 78.2 \\
\hline 12 & 70.0 & 69.9 & 4" & 71.7 & 71.8 \\
\hline 13 & 49.5 & 49.5 & $5^{\prime \prime}$ & 78.3 & 78.3 \\
\hline 14 & 51.0 & 51.0 & 6" & 62.9 & 62.8 \\
\hline 15 & 31.3 & 31.2 & 20-O-sugar & glc & glc \\
\hline 16 & 26.7 & 26.7 & $1^{\prime \prime \prime}$ & 98.3 & 98.1 \\
\hline 17 & 51.9 & 51.8 & 2"' & 75.2 & 75.2 \\
\hline 18 & 18.0 & 18.0 & 3"' & 79.2 & 79.1 \\
\hline 19 & 20.4 & 20.4 & 4"' & 71.7 & 71.7 \\
\hline 20 & 83.3 & 83.4 & $5 " '$ & 78.3 & 77.0 \\
\hline 21 & 22.5 & 22.5 & 6"' & 62.8 & 70.3 \\
\hline 22 & 36.4 & 36.4 & & & $\operatorname{glc}(1-6)$ \\
\hline 23 & 23.3 & 23.2 & $1 " '$ & & 105.3 \\
\hline 24 & 126.0 & 126.0 & $2^{2 " \prime}$ & & 74.9 \\
\hline 25 & 130.9 & 131.1 & 3"'" & & 78.3 \\
\hline 26 & 25.7 & 25.7 & 4"'" & & 71.8 \\
\hline 27 & 17.8 & 17.9 & 5"'" & & 78.3 \\
\hline 28 & 28.1 & 28.1 & 6""' & & 62.8 \\
\hline 29 & 24.2 & 24.1 & & & \\
\hline 30 & 16.9 & 16.9 & & & \\
\hline
\end{tabular}

\section{Experimental}

\subsection{General}

ESI mass spectra were recorded on an LC-MSD trap VL mass spectrometer (Agilent Technologies, Palo Alto, CA, USA). NMR spectra were recorded on a Bruker AV-400 spectrometer $\left(\mathrm{C}_{5} \mathrm{D}_{5} \mathrm{~N}\right.$ used as solvent and TMS as an internal standard). Column chromatography was performed with D-101 macroporous absorption resin (Haiguang Chemical Industrial Company, Tianjin, China) and silica gel (200-300 mesh, Qingdao Marine Chemical Group Co., Qingdao, China). Medium Pressure Liquid Chromatography (MPLC, Büchi, Switzerland) and Agilent 1100 Series prep-HPLC apparatus (Palo Alto, CA, USA) were also used for further isolation. For detection, HPLC was performed on an Agilent 1100 series HPLC apparatus. A Zorbax SB-C18 column $(250 \mathrm{~mm} \times 4.6 \mathrm{~mm}$, I.D., $5 \mu \mathrm{m})$ and a Zorbax SB-C18 guard column $(12.5 \mathrm{~mm} \times 4.6 \mathrm{~mm}$ I.D., $5 \mu \mathrm{m})$ were used at a $25^{\circ} \mathrm{C}$. The mobile phase consisted of water (A) and acetonitrile (B), the detection wavelength was set at $203 \mathrm{~nm}$. D-Glucose and pyridine (Reagent Plus, $\geq 99 \%$ ) were purchased from Sigma (St. Louis, MO, USA). Trifluoroacetic acid (TFA, 99\%) was purchased from Riedel-de Haën (Seelze, Germany). 
GC-MS was performed on an Agilent 6890 gas chromatography instrument coupled with an Agilent 5973 mass spectrometer (Agilent Technologies, Palo Alto, CA, USA).

\subsection{Plant Material}

The roots of $P$. notoginseng were collected in Wenshan region, Yunnan province, China. The botanical origin of material was identified by Dr. Xiu-ming Cui, Wenshan Prefecture Sanqi Research Institute, Yunnan Province. The voucher specimen was deposited at the Institute of Chinese Medical Sciences, University of Macau, Macao, China.

\subsection{Extraction and Isolation}

Air-dried, powdered roots $(2.5 \mathrm{~kg})$ of $P$. notoginseng were extracted three times with boiling methanol (20 L $\times 3 ; 4 \mathrm{~h}, 2 \mathrm{~h}$ and $2 \mathrm{~h}$, respectively). After filtration, excess solvent was removed on a rotary evaporator (Büchi Labortechnik AG, Switzerland) at $60{ }^{\circ} \mathrm{C}$. The residue was suspended in distilled $\mathrm{H}_{2} \mathrm{O}$, and subjected to the D-101 macroporous absorption resin eluting with $\mathrm{H}_{2} \mathrm{O}, 20 \% \mathrm{EtOH}$ and $80 \% \mathrm{EtOH}(\mathrm{v} / \mathrm{v}$, aqueous-EtOH) in sequence. The $80 \% \mathrm{EtOH}$ fraction was collected as total crude saponin. The total crude saponin (210 g) was reloaded on the macroporous column and eluted with $\mathrm{H}_{2} \mathrm{O}, 35 \% \mathrm{EtOH}$ and $80 \% \mathrm{EtOH}(\mathrm{v} / \mathrm{v}$, aqueous-EtOH) [28] to provide a protopanaxatriol saponin fraction (PTS, I), a protopanaxadiol saponin fraction (PDS, II) and a mixture of PTS and PDS (III). The three fractions were dried in the rotary evaporator and weighed $112 \mathrm{~g}, 94 \mathrm{~g}$ and $14 \mathrm{~g}$, respectively. Fraction I (14.5 g) was separated on silica gel column eluting with EtOAc-MeOH- $\mathrm{H}_{2} \mathrm{O}(90: 10: 1$, 85:15:1, 80:20:2 and 75:25:2) and followed MPLC to give the pure compounds notoginsenoside R1 (3, $1.35 \mathrm{~g})$, ginsenoside $\operatorname{Rg} 1$ (4, 7g,) and ginsenoside 5 (Re, $0.52 \mathrm{~g}$ ). Fraction II (30 g) was loaded on a silica gel column, and eluted with EtOAc-MeOH- $\mathrm{H}_{2} \mathrm{O}(85: 15: 3,80: 20: 3$, 70:30:3) to afford ginsenoside Rb1 (14,5.7 g) and two major fractions (IV and V). Fraction IV was separated by PrepHPLC on a $\mathrm{C}_{18}$ column with $\mathrm{MeOH}-\mathrm{H}_{2} \mathrm{O}$ (68:32) to give ginsenosides $\mathrm{R} 2$ (6, $\left.6 \mathrm{mg}\right), \mathrm{Rg} 2$ (7, $\left.10 \mathrm{mg}\right)$ and Rh1 (8, $3 \mathrm{mg})$. Fraction VI was separated by Prep-HPLC with $\mathrm{MeOH}-\mathrm{H}_{2} \mathrm{O}(76: 24)$ on the same $\mathrm{C}_{18}$ column as above and resulted in the isolation of chikusetsusaponin L5 (9, $\left.10 \mathrm{mg}\right)$, malonylginsenoside $\mathrm{Rb} 1$ (15, $5 \mathrm{mg}$ ), ginsenoside $\mathrm{Rd}(\mathbf{1 6}, 1.5 \mathrm{~g}$ ), notoginsenoside $\mathrm{K}$ (17, $40 \mathrm{mg}$ ), quinquenoside R1 (18, <1 $\mathrm{mg})$, and 5,6-didehydro-ginsenoside $\mathrm{Rd}(\mathbf{1}, 2 \mathrm{mg})$. Fraction III was separated by Prep-HPLC with $\mathrm{MeOH}-\mathrm{H}_{2} \mathrm{O}$ (68:32) on the same $\mathrm{C}_{18}$ column as above and resulted in the isolation of notoginsinoside $\mathrm{T}(\mathbf{1 2}, 42 \mathrm{mg}), \mathrm{R} 4(\mathbf{1 1}, 68 \mathrm{mg}), \mathrm{Ra} 3(\mathbf{1 3}, 40 \mathrm{mg}), \mathrm{Fa}(\mathbf{1 0}, 95 \mathrm{mg})$ and 5,6-didehydroginsenoside Rb1 (2, $26 \mathrm{mg})$. Two $\mathrm{mg}$ of quinquenoside R1 (18) and $20 \mathrm{mg}$ of 5,6didehydroginsenoside $\mathrm{Rd}(\mathbf{1})$ were isolated from the remaining fraction II by the same procedure described above.

5,6-Didehyroginsenoside $R d(\mathbf{1})$ was obtained as a white amorphous solid. $[\alpha]_{\mathrm{D}}^{25}=+3.8^{\circ}(c 0.08$, $\mathrm{MeOH})$. ESI-MS m/z 979.5 [M+Cl] $^{-}, 943[\mathrm{M}-\mathrm{H}]^{-}, 781$ [M-H-Glc] $^{-}, 619$ [M-H-2Glc] ${ }^{-}, 457$ [M-H3Glc] ${ }^{-}{ }^{1} \mathrm{H}-\mathrm{NMR}\left(\mathrm{C}_{5} \mathrm{D}_{5} \mathrm{~N}, 400 \mathrm{MHz}\right) \delta_{\mathrm{H}}: 0.91\left(3 \mathrm{H}, \mathrm{s}, \mathrm{H}_{3}-18\right), 0.99\left(3 \mathrm{H}, \mathrm{s}, \mathrm{H}_{3}-30\right), 1.09\left(3 \mathrm{H}, \mathrm{s}, \mathrm{H}_{3}-19\right)$, $1.42\left(3 \mathrm{H}, \mathrm{s}, \mathrm{H}_{3}-29\right), 1.49$ (3H, s, H $\left.3-28\right), 1.58\left(6 \mathrm{H}, \mathrm{s}, \mathrm{H}_{3}-26,27\right), 1.61\left(3 \mathrm{H}, \mathrm{s}, \mathrm{H}_{3}-21\right), 3.30$ (1H, dd, $J=11.6,4.4 \mathrm{~Hz}, \mathrm{H}-3), 5.24$ (1H, t-like, H-24), 5.59 (1H, m, H-6), 4.87 (1H, d, $J=7.5 \mathrm{~Hz}, \mathrm{H}-1$ ' of glc), 
$5.17(1 \mathrm{H}, \mathrm{d}, J=7.8 \mathrm{~Hz}, \mathrm{H}-1$ "' of glc $), 5.34\left(1 \mathrm{H}, \mathrm{d}, J=7.8 \mathrm{~Hz}, \mathrm{H}-1 "\right.$ of glc). ${ }^{13} \mathrm{C}-\mathrm{NMR}$ : see Table 1.

5,6-Didehyroginsenoside Rbl (2) was obtained as a white amorphous solid. $[\alpha]_{\mathrm{D}}^{25}=+16.9^{\circ}(c 0.05$, $\mathrm{MeOH})$. ESI-MS m/z 1141.6 [M+Cl] ; $1105[\mathrm{M}-\mathrm{H}]^{-}, 943[\mathrm{M}-\mathrm{H}-\mathrm{Glc}]^{-}, 925\left[\mathrm{M}-\mathrm{H}-\mathrm{Glc}^{-} \mathrm{H}_{2} \mathrm{O}\right]^{-}, 781$ $[\mathrm{M}-\mathrm{H}-2 \mathrm{Glc}]^{-}, 763\left[\mathrm{M}-\mathrm{H}-2 \mathrm{Glc}-\mathrm{H}_{2} \mathrm{O}\right]^{-}, 619[\mathrm{M}-\mathrm{H}-3 \mathrm{Glc}]^{-} .{ }^{1} \mathrm{H}-\mathrm{NMR}\left(\mathrm{C}_{5} \mathrm{D}_{5} \mathrm{~N}, 400 \mathrm{MHz}\right) \delta_{\mathrm{H}}: 0.92$ (3H, s, H3-18), 0.99 (3H, s, H $\left.\mathrm{H}_{3}-30\right), 1.09$ (3H, s, H $\left.3-19\right), 1.42$ (3H, s, H $\left.3-29\right), 1.49$ (3H, s, H $\left.3-28\right), 1.58$ (3H, s, H $\left.\mathrm{H}_{3}-26\right), 1.64\left(3 \mathrm{H}, \mathrm{s}, \mathrm{H}_{3}-21\right), 1.64\left(3 \mathrm{H}, \mathrm{s}, \mathrm{H}_{3}-27\right), 3.31$ (1H, dd, $\left.J=11.5,4.2 \mathrm{~Hz}, \mathrm{H}-3\right), 5.31(1 \mathrm{H}$, t-like, H-24), 5.59 (1H, br s, H-6), 4.88 (1H, d, $J=7.3 \mathrm{~Hz}, \mathrm{H}-1$ ' of glc), 5.04 (1H, d, $J=7.7 \mathrm{~Hz}, \mathrm{H}-1$ "'" of glc), $5.12\left(1 \mathrm{H}, \mathrm{d}, J=7.8 \mathrm{~Hz}, \mathrm{H}-1\right.$ "' of glc), $5.36(1 \mathrm{H}, \mathrm{d}, J=7.8 \mathrm{~Hz}, \mathrm{H}-1$ " of glc $) .{ }^{13} \mathrm{C}-\mathrm{NMR}$ : see Table 1.

\subsection{Acidic Hydrolysis of Compounds $\mathbf{1}$ and $\mathbf{2}$}

Each sample $(1 \mathrm{mg})$ was hydrolyzed with $2 \mathrm{~mol} \cdot \mathrm{L}^{-1} \mathrm{TFA}(1 \mathrm{~mL})$ at $100{ }^{\circ} \mathrm{C}$ for $2 \mathrm{~h}$ in a sealed glass tube with a screw cap which was filled with pure nitrogen gas. The hydrolyzed solution was evaporated to dryness under $45^{\circ} \mathrm{C}$ and then methanol $(1 \mathrm{~mL})$ was added for further evaporation and complete removal of TFA. The hydrolysate was treated with $1 \mathrm{~mL}$ hydroxylamine hydrochloridepyridine solution $\left(20 \mathrm{mg} \cdot \mathrm{mL}^{-1}\right)$ at $90{ }^{\circ} \mathrm{C}$ for $30 \mathrm{~min}$ in a sealed glass tube fitted with a screw cap. After cooling to room temperature, acetic anhydride $(1 \mathrm{~mL})$ was added and heating continued for another 30 min in the resealed tube. The cooled solution was evaporated to dryness under reduced pressure at 45 ${ }^{\circ} \mathrm{C}$. The residue was dissolved in dry chloroform $(2 \mathrm{~mL})$. The solution was filtered through a $0.45 \mu \mathrm{m}$ syringe filter (Agilent Technologies) prior to injection into GC-MS system. GC-MS was carried out on a HP-5MS capillary column $(30 \mathrm{~m} \times 0.25 \mathrm{~mm}$, i.d. $)$ coated with $0.25 \mu \mathrm{m}$ film $5 \%$ phenyl methyl siloxane. The column temperature was set at $175^{\circ} \mathrm{C}$ and held for $7 \mathrm{~min}$, then programmed at $5{ }^{\circ} \mathrm{C} \cdot \mathrm{min}^{-1}$ to $185^{\circ} \mathrm{C}$ and held for $5 \mathrm{~min}$, then at $4{ }^{\circ} \mathrm{C} \cdot \mathrm{min}^{-1}$ to $230^{\circ} \mathrm{C}$. Split injection $(2 \mu \mathrm{L})$ with a split ratio of 1:50 was applied. High purity helium was used as carrier gas with flow rate of $1.0 \mathrm{~mL} \cdot \mathrm{min}^{-1}$. The mass spectrometer was operated in electron-impact (EI) mode, the scan range was 40-550 amu, the ionization energy was $70 \mathrm{eV}$ and the scan rate was $2.89 \mathrm{~s}$ per scan. The inlet, ionization source temperature were 250 and $280{ }^{\circ} \mathrm{C}$, respectively. The same reaction and analysis were applied for standard sugar (D-glucose). The D-glucose derivative showed a peak at $t_{\mathrm{R}} 12.5 \mathrm{~min}$. As a result, Dglucose was detected from both $\mathbf{1}$ and 2.

\section{Conclusions}

In this study, the glycosidic fraction from the roots of $P$. notoginseng was investigated. Two novel saponins, 5,6-didehydroginsenoside $\mathrm{Rd}$ (1) and 5,6-didehydroginsenoside $\mathrm{Rb} 1$ (2), were isolated from the roots of $P$. notoginseng, along with sixteen known saponins. This result will be helpful to better understand the chemical components of $P$. notoginseng.

\section{Acknowledgements}

This research was supported by grants from Macao Science and Technology Development Fund (013/2008/A1) and Research committee of University of Macau (UL016/09-Y1/CMS/WYT01/ICMS). 


\section{References}

1. Wan, J.B.; Wang, Y.T.; Li, S.P. Chinese Herbs: Pharmacological Activities and Quality Control; Li, S.P., Wang, Y.T., Eds.; Nova Science Publishers: New York, NY, USA, 2008; pp. 179-203.

2. Konoshima, T.; Takasaki, M.; Tokuda, H. Anti-carcinogenic activity of the roots of Panax notoginseng. II. Biol. Pharm. Bull. 1999, 22, 1150-1152.

3. Liu, S.J.; Zhou, S.W. Panax notoginseng saponins attenuated cisplatin-induced nephrotoxicity. Acta Pharmacol. Sin. 2000, 21, 257-260.

4. Sun, H.X.; Ye, Y.P.; Pan, H.J.; Pan, Y.J. Adjuvant effect of Panax notoginseng saponins on the immune responses to ovalbumin in mice. Vaccine 2004, 22, 3882-3889.

5. Rhule, A.; Navarro, S.; Smith, J.R.; Shepherd, D.M. Panax notoginseng attenuates LPS-induced pro-inflammatory mediators in RAW264.7 cells. J. Ethnopharmacol. 2006, 106, 121-128.

6. Li, B.J.; Zhang, B.H. Studies on the antiarrhythmic effects of panaxatriol saponins (PTS) isolated from Panax notoginseng. Acta Pharm. Sin. 1988, 23, 168-173.

7. Liu, J.; Liu, Y.; Klaassen, C.D. The effect of Chinese hepatoprotective medicines on experimental liver injury in mice. J. Ethnopharmacol. 1994, 42, 183-191.

8. Cicero, A.F.; Vitale, G.; Savino, G.; Arletti, R. Panax notoginseng (Burk.) effects on fibrinogen and lipid plasma level in rats fed on a high-fat diet. Phytother. Res. 2003, 17, 174-178.

9. Ng, T.B. Pharmacological activity of sanchi ginseng (Panax notoginseng). J. Pharm. Pharmacol. 2006, 58, 1007-1019.

10. Wang, C.Z.; McEntee, E.; Wicks, S.; Wu, J.A.; Yuan, C.S. Phytochemical and analytical studies of Panax notoginseng (Burk.) F.H. Chen. J. Nat. Med. 2006, 60, 97-106.

11. Thong, N.V.; Toan, L.D. Effect of Luotai (panax notoginseng saponin) in acute ischemic stroke. J. Neurol. Sci. 2009, 285, S230.

12. Sun. H.X.; Yang, Z.G.; Ye, Y.P. Structure and biological activity of protopanaxatriol-type saponins from the roots of Panax notoginseng. Int. Immunopharmcol. 2006, 6, 14-25.

13. Wan, J.B.; Lee, S.M.; Wang, J.D.; Wang, N.; He, C.W.; Wang, Y.T.; Kang, J.X. Panax notoginseng reduces atherosclerotic lesions in ApoE-deficient mice and inhibits TNF- $\alpha$-induced endothelial adhesion molecule expression and monocyte adhesion. J. Agr. Food Chem. 2009, 57, 6692-6697.

14. Zhou, J.; Wu, M.Z.; Taniyasu, S.; Besso, H.; Tanaka, O.; Saruwatari, Y.; Fuwa, T. Dammaranesaponins of sanqi-ginseng, roots of Panax notoginseng: structures of new saponins, notoginsenosides-R1 and -R2, and identification of ginsenoside-Rg2 and Rh1. Chem. Pharm. Bull. 1981, 29, 2844-2850.

15. Yang, T. R.; Kasai, R.; Zhou, J.; Tanaka, O. Dammarane saponins of leaves and seeds of Panax notoginseng. Phytochemistry 1983, 22, 1473-1478.

16. Matsuura, H.; Kasai, R.; Tanaka, O.; Saruwatari, Y.I.; Fuwa, T.; Zhou, J. Further Studies on Dammarane-saponins of Sanchi-Genseng. Chem. Pharm. Bull. 1983, 31, 2281-2287.

17. Yoshikawa, M.; Morikawa, T.; Kashima, Y.N.K.; Matsuda, H. Structures of new dammarane-type triterpene saponins from the flower buds of Panax notoginseng and hepatoprotective effects of principal ginseng saponins. J. Nat. Prod. 2003, 66, 922-927. 
18. Ma, W.G.; Mizutani, M.; Malterud, K.E.; Lu, S.L.; Ducrey, B.; Tahara, S. Saponins from the roots of Panax notoginseng. Phytochemistry 1999, 52, 1133-1139.

19. Nagai, Y.; Tanaka, O.; Shibata, S. Chemical studies on the oriental plant drugs XXIV Structure of ginsenoside Rg1, A neutral saponin of ginseng root. Tetrahedron 1971, 27, 881-883.

20. Sanada, S.; Konodo, N.; Shoji, J.; Tanaka, O.; Shibata, S. Studies on the saponins of ginseng. I structure of ginsenoside -Re,-Rf and Rg2. Chem. Pharm. Bull. 1974, 22, 2407-2412.

21. Matsuura, H.; Kasai, R.; Tanaka, O.; Saruwatari, Y.; Kimihiro, K.; Fuwa, T. Further studies on dammarane-saponins of ginseng roots. Chem. Pharm. Bull. 1984, 32, 1188-1192.

22. Sanada, S.; Kondo, N.; Shoji, J.; Tanaka, O.; Shibata, S. Studies on the saponing of ginseng (1) structure of a ginsenoside Ro, Rb1, Rd. Chem. Pharm. Bull. 1974, 22, 421-428.

23. Yahara, S.; Kasai, R.; Tanaka, O. New dammarane type saponins of leaves of Panax japonicus C. A. Mayer. (1). Chikusetsusaponins L-5, L9a and L10. Chem. Pharm. Bull. 1977, 25, 2041-2047.

24. Kitagawa, I.; Taniyama T.; Yoshikawa, M.; Ikenishi, Y.; Nakagawa, Y. Chemical studies on crude drug processing. VI. Chemical structures of malonyl-ginsenosides Rb1, Rb2, Rc, and Rd isolated from the root of Panax ginseng C. A. Meyer. Chem. Pharm. Bull. 1989, 37, 2961-2970.

25. Besso, H.; Kasai, R.; Wei, J.; Wang, J.F.; Saruwatari, Y.; Fuwa, T.; Tanaka, O. Further studies on dammarane-saponins of American Ginseng, roots of Panax quinquefolium L. Chem. Pharm. Bull. 1982, 30, 4534-4538.

26. Tanaka, O. Application of ${ }^{13} \mathrm{C}$-Nuclear magnetic resonance spectrometry to structural studies on glycosides: saponins of Panax spp. and natural sweet glycosides. Yakugaku Zasshi 1985, 105, 323-351.

27. Zhong, S.; Guan, S. The application of TOCSY1D to the NMR complete assignments of ginsenoside-Rd. Mod. Instrum. 2004, 10, 18-21.

28. Wan, J.B.; Zhang, Q.W.; Ye, W.C.; Wang, Y.T. Quantification and separation of protopanaxatriol and protopanaxadiol type saponins from Panax notoginseng with macroporous resins. Sep. Purif. Technol. 2008, 60, 198-205.

Sample Availability: Samples of the compounds are available from the authors.

(C) 2010 by the authors; licensee MDPI, Basel, Switzerland. This article is an open access article distributed under the terms and conditions of the Creative Commons Attribution license (http://creativecommons.org/licenses/by/3.0/). 